Book review

\title{
Regulatory impact assessment - towards better regulation
}

Colin Kirkpatrick and David Parker (eds)

Reviewed by

Anjali Garg, Fellow

Centre for Regulatory Impact Assessment

Regulatory Studies and Governance Division

TERI, New Delhi

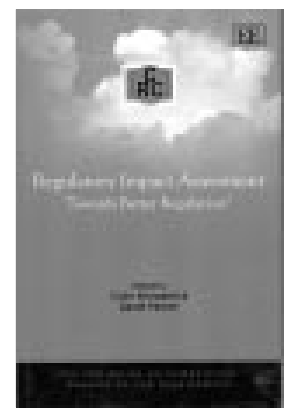

Hardcover

286 pp. 2007

ISBN 978-1-84542-412-1

International Journal of Regulation and Governance 8(1): 93-96

Regulatory impact assessment or RIA is a tool for providing systematic assessment of positive and negative impacts of the proposed and existing regulations, with the aim of improving the quality of a regulatory policy. International experience reveals that RIA is currently being used significantly in a number of countries around the world. In several of these countries, RIA was developed as a response to the growing volume and complexity of government regulations in the 1980s. RIA has been adopted in most OECD (Organisation for Economic Co-operation and Development) countries, and at the beginning of 2001, 20 out of the 28 member countries were applying RIA, although the extent of use varied.

This book brings together various research studies undertaken on regulatory impact assessment by the Centre on Regulation and Competition of the University of Manchester, UK, and its research partners both in the UK and overseas in China, Ghana, India, Malaysia, the Philippines, South Africa, and Sri Lanka. The work undertaken by the Centre has been funded primarily by the UK's Department for International Development with support from the UK Foreign and Commonwealth Office's Global Opportunities Fund and the British Council. Other collaborating agencies include the Foreign Investment Advisory Service of the World Bank and the Competition Division of the UNCTAD (United Nations Committee on Trade and Development). 
This book explains the concept of RIA and its principles in detail. It looks at the experience of developed as well as developing countries including UK, Europe (European Commission and South-east Europe), Australia, Mexico, East Africa, and Sri Lanka. The book builds on the concept of RIA and discusses the critical elements of the RIA process in detail - targeting and scope, public consultation, quality control and data collection methods, and data quality standards.

The book clearly brings out the fact that there is an increased focus in most developed countries on reducing administrative burden targets to improve the quality of regulation. There is substantial discussion in the book on RIA in the UK - its evolution, development, and auditing. The UK has a strong base of RIA experience, and is doing well in areas like public consultation, streamlining the IA process, and improved accountability. However, the various evaluation reports of the NAO (National Audit Office), UK, emphasize that in general, RIAs are still often seen as a paper output rather than an integral part of the process of policy-making. It is interesting to note here that despite facing several constraints in implementation, there is almost universal acceptance and recognition of the fact that RIAs have undoubtedly led to greater transparency, participation, and accountability among decision-makers in the UK. At the same time, the discussion in the book on RIA in Australia concludes that while RIA has contributed significantly to improved regulatory quality, its role has been secondary to other initiatives like the $\mathrm{Na}-$ tional Competition Policy Programme, and the logic underlying RIA has not yet been fully embedded in the regulatory process.

The deliberation on the experience vis-à-vis RIA in the developed countries has important implications for developing countries. It is seen that despite the considerable interest in measuring the effectiveness of development policy and in the design and implementation of regulation measures, it appears that the potential of RIA has neither been explored nor analysed in the developing countries and in the organizations involved in the design and formulation of the development policy. RIA has been undertaken in middle-income developing countries, especially South Korea and Mexico. Although there has been some interest in the concept among the Asia-Pacific Economic Cooperation members and in certain parts of the central and Eastern Europe, it appears that there has been very little progress in adopting RIA in these regions. In Africa, the Middle East, and 
much of Asia, it seems that RIA has not been seriously considered by the government or perhaps has not been known at all.

There is an interesting discussion in the book on the application of RIA in developing countries. This discussion also draws from the findings of a questionnaire survey undertaken by the authors of this particular chapter. The questionnaire study on the actual use of RIA was sent to regulators in a large number of lower- and middle-income economies. The results of this study confirm that a number of difficulties exist in this area and conclude that while RIA has the potential to improve regulatory governance in these economies, one should not underestimate the difficulty of introducing and operating effective RIA processes.

The book has important lessons and learnings for the developing world, which is now increasingly recognizing the fact that a favourable business climate could not only facilitate private investment and competition but also increase economy-wide growth, productivity, and employment opportunities. Empirical research (including investment climate assessments of the World Bank) has also established a strong correlation between investment climate, private sector performance, and poverty, especially in the developing countries. For successfully institutionalizing business regulation reforms, it is imperative to adopt and develop certain key principles such as building strong political consensus, an inclusive consultation mechanism, effective communication strategy, capacity building on regulatory matters, better centre-state coordination, effective use of information technology, and lastly, gathering support of all stakeholders.

The section that discusses RIA in East Africa is of specific relevance to other developing countries in Asia and Africa. As clearly brought out in this section, it is extremely important to note that the RIA methodologies used in the OECD countries need amendment in the context of developing country in terms of availability of resources, data, and human resources, institutional strength, and the extent of political support available. It also brings out the relevance of training and capacity building in these countries. The carrying out of RIA requires technical skills that often go beyond the training of officials. Properly designed programmes must be organized to give regulators the skills needed to carry out high quality RIA, covering detailed methodologies of impact assessment. However, for any RIA process to 
be effective, training should also target civil society, business organizations, and parliamentarians.

The book provides the basic information on the techniques of RIA: benefit-cost analysis, cost-effectiveness analysis, partial analysis, and risk assessment and uncertainty analysis. However, apart from this, the book should have discussed in greater detail as to how these techniques are used, providing detailed examples of actual RIAs undertaken. This would help policy-makers and researchers in those countries where RIA is not yet a part of the policy-making process.

The book is of enormous significance to policy-makers, researchers, and academicians in developed, developing, and transitional economies as it provides not only the essential foundation of principles of RIA but also supplements it with successful and not-so-successful case studies from various countries. 